\title{
Design Modification of Automated Power Window Circuit System for Automobiles Air -Condition
}

\author{
Joseph Sekyi-Ansah*1, James Kwasi Quaisie ${ }^{2}$, Isaac Eduyah ${ }^{1}$, Mohammed Okoe Alhassan ${ }^{1}$, Eric Quansah ${ }^{1}$, \\ Esther Kyere Andoh-Acquah ${ }^{1}$ \\ ${ }^{1}$ Department of Mechanical Engineering, Takoradi Technical University, Takoradi, 00233, Ghana. \\ ${ }^{2}$ School of Mechanical Engineering, Jiangsu University, Zhenjiang, Jiangsu 212013, China. \\ Corresponding Author : sekyiansahj@yahoo.com
}

\author{
Article Info \\ Volume 7, Issue 4 \\ Page Number: 264-270 \\ Publication Issue : \\ July-August-2020
}

\section{Article History}

Accepted : 15 Aug 2020

Published : 22 Aug 2020

\section{ABSTRACT}

Air conditioning has become a key component in the automobile industry now, and almost every vehicle manufactured in the 21 st century has air conditioning integrated. Most drivers drive with their air conditioning on while some of their windows are not fully closed; this affects the operation of the air conditioning. In addition, if the driver wants to turn on the air conditioning while driving, he or she has to move up the power windows manually after or before he or she turns on the air conditioning, which may affect his or her concentration on the road. The concept of this power window circuit system is to automatically close the windows after a few seconds when the air conditioner is turned on.

Keywords: Air Conditioning; Automobile; Power Window; Circuit; Electromechanical; Vehicle Operation.

\section{INTRODUCTION}

The contemporary automobile has an extensive electric system with a great many electrical, electromechanical and electronic loads, which are central to the operation of the engine, passenger safety and comfort such as air conditions.[1-3]. The air conditioning $(\mathrm{AC})$ system $[4,5]$ provides the electric vehicle cabin with heating, air conditioning and ventilation $[6,7]$. The internal thermal conditions of the vehicle need to be monitored and visibility protection assured [8]. Since electrically powered AC systems, the range of vehicles is dramatically decreased if the AC system operates [9, 10]. Most studies have been conducted in the area of automobile air condition systems, which all seem to find varies solutions to their numerous problems. Datta and Das [11] studied the performance of an automotive air conditioning system with storage battery state - of charge variation. Their study reveals that during the gradual derivation of the supply voltage the typical deterioration of the cooling capacity and the system COP. Li and Sun [12] conducted numerical simulation and analysis of air conditioning system integrated with passenger compartment for transport. Their investigation was first carried out without air 
conditioning unit on a compartment. Their results from calculating the cooling load for a passenger compartment made them understand how the cooling load is affected by solar time, room design temperature, the fresh air volume and automobile speed. After a solar time, there was a maximum cooling load. As vehicle speed increases to a certain velocity, the cooling load will no longer decrease. The volume of fresh air and the temperature of room design have a major impact on the refrigeration load. Mansour et al. [13] developed a novel control strategy for multi-circuit roof bus air - conditioning in hot, humid countries to enhance energy efficiency and enhance the thermal comfort of passengers. In their research, a comparison of output was made between that of the conventional AC system [14] and that of the newly developed one. Their comparison revealed that, under different partial load conditions, the adopted control strategy makes significant improvements in terms of thermal comfort and energy saving. It could achieve potential energy savings of up to 31.6 percent. $\mathrm{Ng}$ et al. [15] used adaptive neural predictive control for an air conditioning system in an aeroplane. Their experimental results indicate the superiority of the proposed control scheme in terms of reference tracking as well as disturbance rejection due to its adaptability in catching AAC device behaviour in real-time over the wide range of operating conditions. Joudi et al. [16] conducted a computer and experimental study of an automotive air conditioning system with alternative refrigerants. The results showed good agreement with the literature's current experimental and theoretical results. From the analysis reported, it shows that there is still work to be done in the automotive air conditioning system field.

The purpose of this study identifies that most drivers drive with their air conditioning cars without their windows fully closed and this affects the operation of the air conditioning system. Therefore, there is a need to design and modify an automated power window circuit that will automatically close the vehicle windows immediately the AC is turned on.

\section{Methodology of the Study}

The method is used to achieve the objective of the project that will accomplish a perfect result. To evaluate this project, the methodology adopted was based on the System Development Life Cycle (SDLC), shown in Figure 1. Generally, involve three major steps, namely; planning, implementing, and analysis.

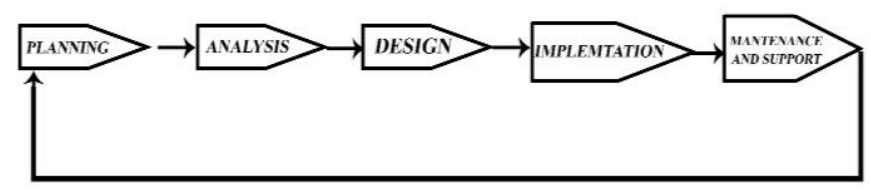

Fig. 1. SLDC Phase

From the three major steps for implementing projects. All the methods used for finding and analyzing data regarding the project are related in Figure 2.

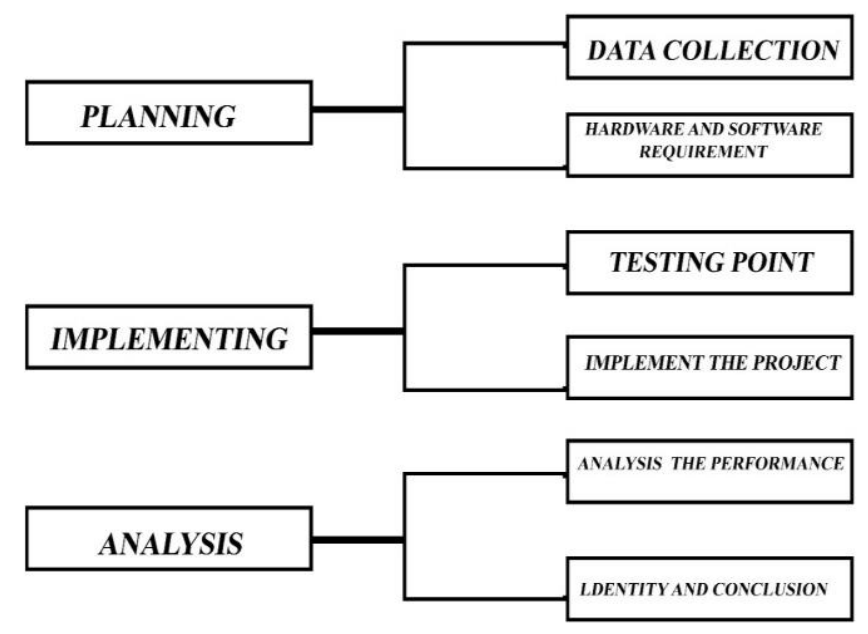

Fig. 2. Steps of methodology

\subsection{Planning}

To identify all the information and requirement such as hardware and software, planning must be done properly. The planning phase has two main elements, namely data collection and the requirements of hardware and software. 


\subsubsection{Data collection}

Data collection is a stage in any area of study. At this stage, we planned the project's resources and requirements, literature studies, and schedule to get more information in this study. Within the data collection period, we found the study about the power window operation, time delay relays, and the air conditioning operation and its related project. Once we got the project manual, we tried to find out the electronic component and other materials and some of the equipment to be used.

While planning, we have researched the project related, which including with study about the electronic component such as motors, fuses, contactors, coils, and diode. The study is not just for the function of the component, but the types of small circuits build by each component related.
2.2 Materials and methods

2.2.1 Characteristics of a power window motor

\section{- Basic Specification}

The power window motor has four whole mounting positions. There is a working voltage of 12 volts DC, shown in Table 1. The unit is waterproof and ISO 9001 certified. The no-load speed or speed when no torque is applied to the motor shaft is 95 rotations per minute (rpm) and the no-load current is less than 1.5 amperes. The stall torque or minimum torque needed to completely stop the motor shaft from rotating, or stall the motor, is less than 8 units or pound-feet (N.m) and the stall current is less than 20A and Table 2 indicate rotation direction of terminal A and $\mathrm{B}$.

\section{Table 1 electrical Specifications}

\begin{tabular}{lll}
\hline \multicolumn{1}{c}{ Item } & Specified value & \multicolumn{1}{c}{ Remarks } \\
\hline Rated voltage & DC $12 \mathrm{~V}$ & Operated normally within this range \\
Operating voltage range & DC $9 \mathrm{~V} \sim \mathrm{DC}$ & - Auto up function is inactive within $9 \mathrm{~V} \sim 10 \mathrm{~V}$ \\
& $16 \mathrm{~V}$ & \\
Operating temperature range & $-35^{\circ} \mathrm{C} \sim+75^{\circ} \mathrm{C}$ & - Data storage and manual operation is possible within $7 \mathrm{~V} \sim 9 \mathrm{~V}$ \\
Storage temperature range & $-40^{\circ} \mathrm{C} \sim+85^{\circ} \mathrm{C}$ & - Stops motor if exceeding $16 \mathrm{~V}$ \\
Max. humidity & $95 \% \mathrm{RH}$ & \\
Power consumption & $33 \mathrm{Ma}$ & No-load included \\
Size and weight & - & Shown in the drawing \\
Current in slip mode & Max. $1 \mathrm{~mA}$ & \\
\hline
\end{tabular}

Table 2 Rotation Direction

\begin{tabular}{ccc}
\hline & Terminal A & Terminal B \\
\hline Clockwise(cw) & - & + \\
Counterclockwise(ccw) & + & - \\
\hline
\end{tabular}




\subsubsection{Motor circuit diagram}

Figure 3 power window motor circuit diagram, indicate the rotor or armature of a DC power window motor consists of current-carrying conductors connected at one end to electrically isolated copper segments called the commutator. The commutator allows an electrical connection to be made via carbon brushes (hence the name "Brushed" motor) to an external power supply as the armature rotates. Figure 4 motor profile indicates the magnetic field set up by the rotor tries to align itself with the stationary stator field causing the rotor to rotate on its axis, but cannot align itself due to commutation delays. The rotational speed of the motor is dependent on the strength of the rotor's magnetic field and the more voltage that is applied to the motor, the faster the rotor will rotate. By varying this applied DC voltage, the rotational speed of the motor can also be varied. PTC thermistors are temperaturedependent resistors based on special semiconductor ceramics with a high positive temperature coefficient (PTC). They exhibit relatively low resistance values at room temperature. When a current flows through a PTC, the heat generated raises the temperature of the PTC. Positive temperature coefficient (PTC) thermistors are used to protect the motor against locked motor conditions, continuous overload, and ambient temperature.

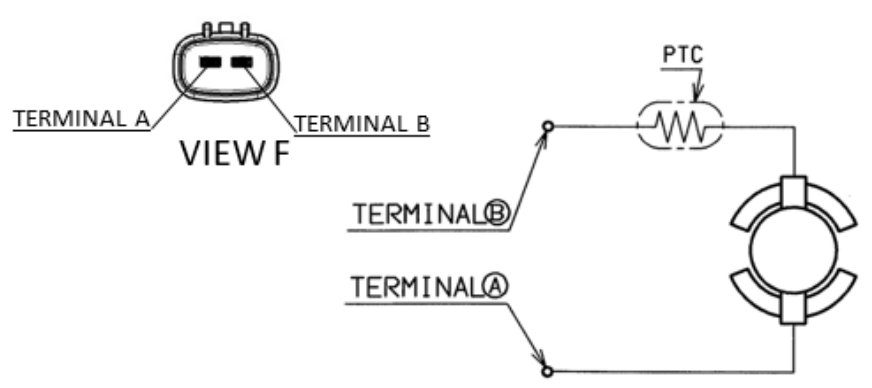

Fig. 3. Power window motor circuit diagram

\section{Motor specification}

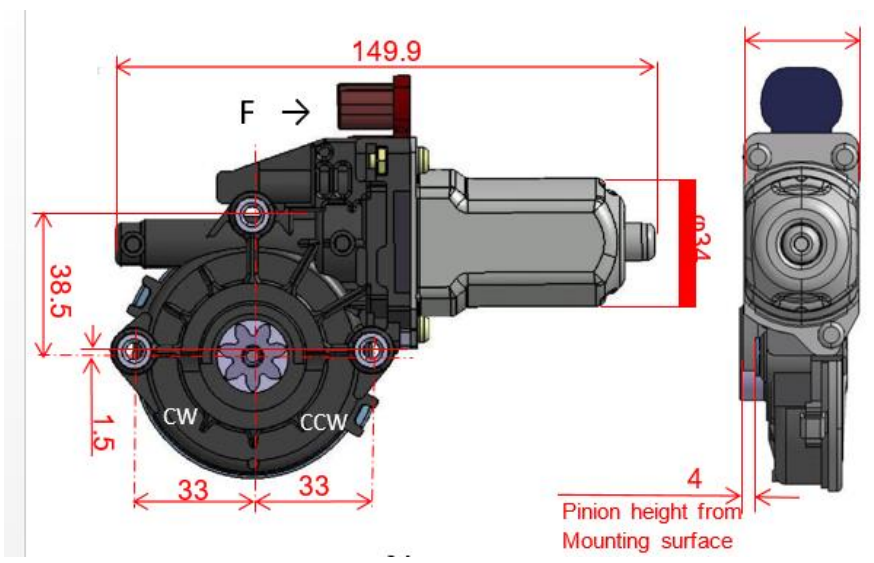

Fig. 4. Motor profile.

\subsubsection{Size of standard car window}

The windows are $2^{\prime} 2^{\prime \prime} \times 2^{\prime} 2^{\prime \prime}$ in size or $24^{\prime \prime} \times 24^{\prime \prime}$ minus the half-inch allowance from both the 0 height and width of the window. When you go to the window installation store and you see a 2020 window, its $231 / 2$ " x $231 \frac{1}{2}$ " in size. Windows differ in height and style by make and model, but the average car window height is 19.5 inches.

\subsubsection{Specifications of on-delay relays}

A Time delay relay is a combination of an electromechanical output relay and a control circuit. The control circuit is comprised of solid-state components and timing circuits that control the operation of the relay and timing range. Typical time delay functions include on-delay, repeat cycle (starting off), interval, off-delay, re-triggerable one shot, repeat cycle (starting on), pulse generator, one-shot, on / off delay, and memory latch. Time delay relays have a broad choice of timing ranges from less than one second to many days, shown in Figure 5. There are many choices of timing adjustments from calibrated external knobs, DIP switches, thumbwheel switches, or recessed potentiometer. The output contacts on the electromechanical output relay are directly wired to the output terminals. The contact load ratings are specified for each specific type of time delay relay. 


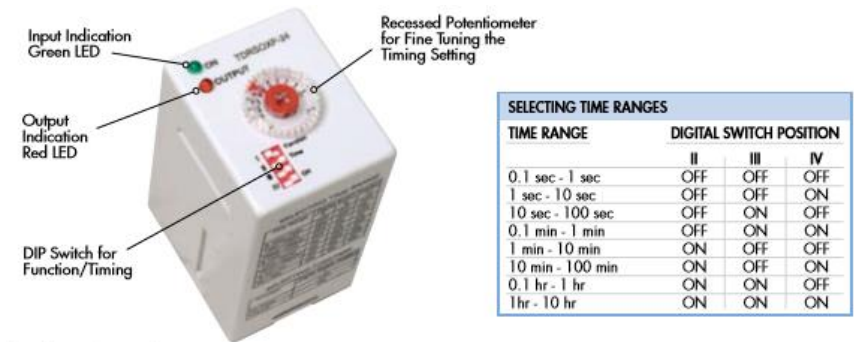

Fig. 5. Specifications of on-delay relays

\subsubsection{Wiring diagram}

The coil wire is connected to pins 2 and 7 on the power source (battery). Pin 1and 3 are connected as a normally open circuit and pin 1 and 4 as normally closed circuits. The other pole has pin 8 and 6 connected as normally open and pins 8 and 5 as normally closed indicate in Figure 6.

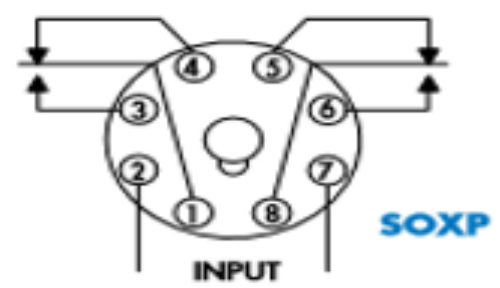

ON DELAY

Fig. 6. Wiring diagram for on-delay relays

\subsubsection{AC Blower Motor}

A blower motor is found in vehicles and is the part of that system responsible for pushing the hot air throughout the vehicle when the heating system is running. It also blows through the vehicle's AC evaporator to provide cool air when the air conditioning system is running shown in Figure 7.

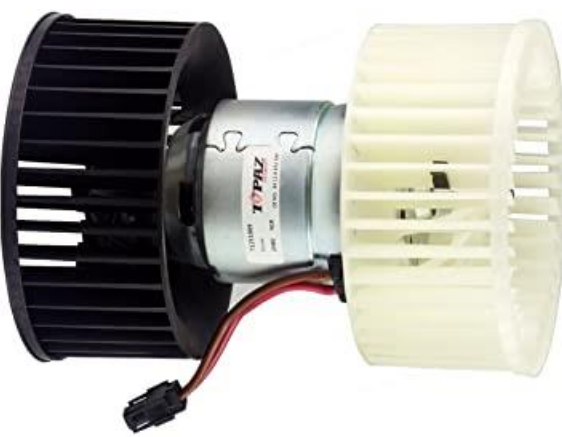

Fig. 7. AC blower

\subsubsection{Fuses}

In electronics and electrical engineering, a fuse is an electrical safety device that operates to provide overcurrent protection of an electrical circuit, as shown in Figure 8. Its essential component is a metal wire or strip that melts when too much current flows through it, thereby stopping or interrupting the current.

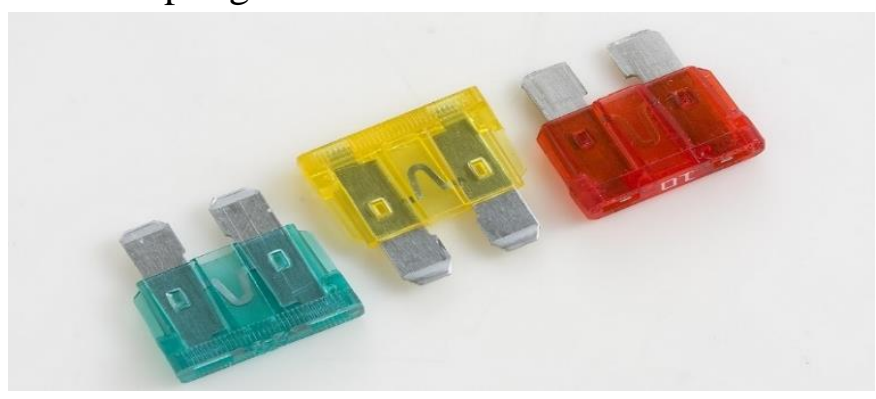

Fig. 8 Fuse

\subsubsection{V Battery}

The battery serves as the power supply for the circuit, as shown in Figure 9.

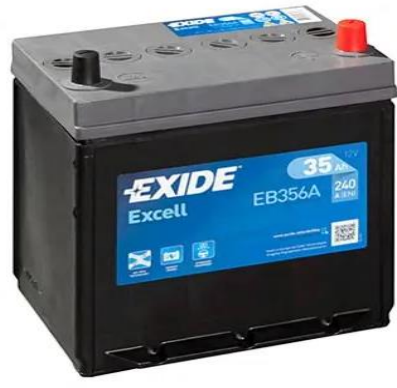

Fig. 9. Battery.

\subsubsection{Wires}

Wires are used for electrical connections as illustrated with different colours in Figure 10.

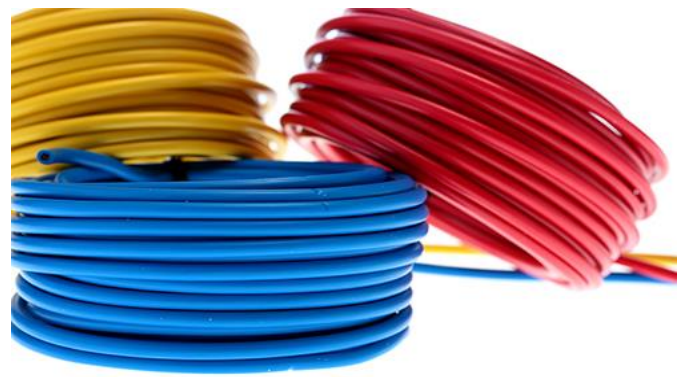

Fig.10. wires. 


\subsubsection{AC Blower Switch}

The AC blower switch is the electrical switch on the interior of a vehicle that allows the driver to control the vehicle's heating and air conditioning system, as indicated in Figure 11. It is usually built into the same control panel that houses all of the $\mathrm{AC}$ system controls and is labelled with numbers and symbols to indicate blower fan speed.

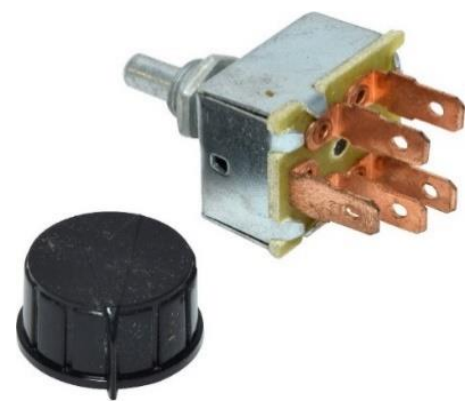

Fig. 11. AC blower switch.

\subsubsection{Circuit connection for AC blower switch}

Figure 12 shows a blower fan is connected to the negative battery terminal (also called ground) on one end and to the positive battery terminal through a blower resistor on the other end. The blower resistor is connected in series with the blower fan. This means that the current running through the blower motor, and thus is speed is controlled by the resistor value. The user chooses a suitable fan speed by using a selector to connect one of the resistors in the blower resistor pack. Blower resistors are made of several resistors with different resistances. There are also two additional circuits used for the off state and the highest fan speed state. In the off state, the blower motor is disconnected from the power supply. In the highest speed state, the blower resistor is bypassed completely and the fan is connected directly to the car's battery, which allows maximum current through the motor. The lower the resistance of the selected resistor in a pack, the higher the current that flows through the blower fan and the faster the fan will turn.
Blower motor

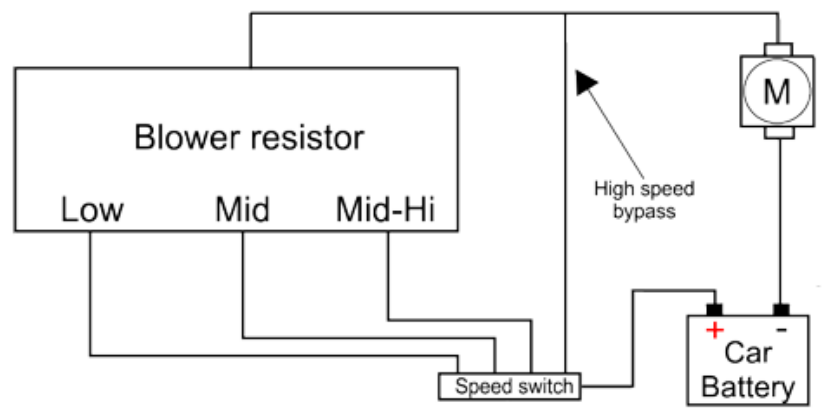

Fig.12 Circuit diagram for AC blower switch (Resistor guide).

\subsection{Test Procedure}

\subsubsection{Software requirement}

For software requirements, we have chosen CADe SIMU Software, version 1.0 (2004). CADe SIMU is a software tool suite used primarily for electronic design simulation. The software is used mainly to create electronic prints for manufacturing of printed circuit boards, by electronic design engineers and electronic technicians to manufacture electronic schematics and diagrams, and for their simulation.

\subsubsection{Wire connection}

Figure 13 indicates the Schematic Diagram designed by CADe SIMU. The positive terminal of the battery is wired to the AC blower switch. From the AC blower switch, the connection is split into two connections. One connection to the AC blower and the other connection to the positive terminal of the first on delay timer with a fuse incorporated in the connection. The instant closed circuit section of the on delay timer is connected to the positive terminal of the buzzer and the delayed closed circuit section is connected to the second on delay timer. From the second on delay timer, the instant closed circuit section is connected to the positive terminal of the power window motor, but there is no connection for delayed closed circuit section. The negative terminal of the battery is wired in four connections. The first connection is to the negative terminal of the AC blower; the second connection is to the negative terminal of the on-delay timers 
and the third connection to the negative terminal of the buzzer and the fourth or last connection to the negative terminal of the power window motor.

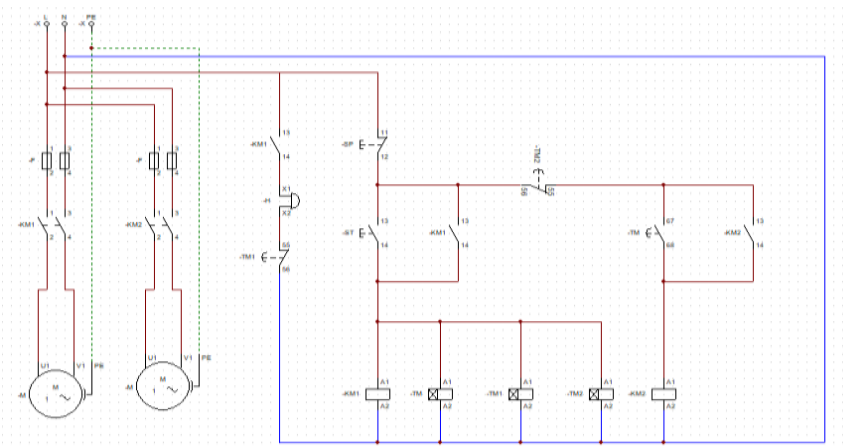

Fig. 13. Schematic Diagram designed by CADe SIMU.

\subsection{3 timing}

The delayed closed section of the first-timer (TM1) is timed for thirty seconds and the delayed closed circuit section of the second timer (TM2) is timed for thirty seconds.

$\mathrm{TM} 1=30$ seconds

TM2 $=30$ seconds

The average height of a car window $=50 \mathrm{~cm}$ Average car window closing duration $=7 \mathrm{secs}$ Therefore, speed of glass $=50 / 7=7.14 \mathrm{~cm} / \mathrm{s}$

\subsubsection{Operation}

When the AC blower is turned on, current flows from the battery to the AC blower and the first on delay timer immediately. The AC starts working and the buzzer starts beeping since it is connected to the instantly closed circuit section of the first on delay timer. After thirty seconds, the instant closed circuit section of the first on delay timer becomes opened and the delayed closed circuit section then becomes closed and current flows to the second on delay timer. The buzzer stops beeping and the power window motor also starts working since it is connected to the instant closed section of the second timer. After thirty seconds, the second timer becomes opened and the power window motor stops working. The AC blower will continue to work until the AC blower switch is turned off.

3.0 Results and discussion
After the whole design has been constructed, it was to test to it perform the required actions need to control electrical components. In the test, the AC blower motor is connected to the output of the circuit via a relay to provide sufficient high currents and voltage compatibility. This discussion entails the performance results of the circuit after it was tested.

\subsection{Performance Test}

\section{- Test 1}

After the circuit has been supplied with a power source (12 volts battery), when the switch on the $\mathrm{AC}$ blower switch immediately the AC blower and the buzzer started working after thirty seconds, the first underlay timer could transfer power to the second timer for the power window to work, it was re-timing and over timing again. So, the AC blower was switched off and we checked through our connections. We realized we had a connection which was the negative supply instead of a positive supply. We re-wired the connection again and ran a second test.

\section{- Test 2}

The power source was supplied to the circuit and the AC blower switch was turned on. The AC blower and the buzzer started working immediately. After thirty seconds, the buzzer stopped beeping and the power window motor began to operate whiles the AC blower was still working. The power window stopped working after thirty seconds and the AC blower was still in operation until the AC blower switch was switched off. Therefore, the results of the second test show that our connections were successfully executed.

\subsection{Presentation of results}

Figure 3.1 shows an image of the finished construction of the automated power window circuit for vehicles with air conditioning. 


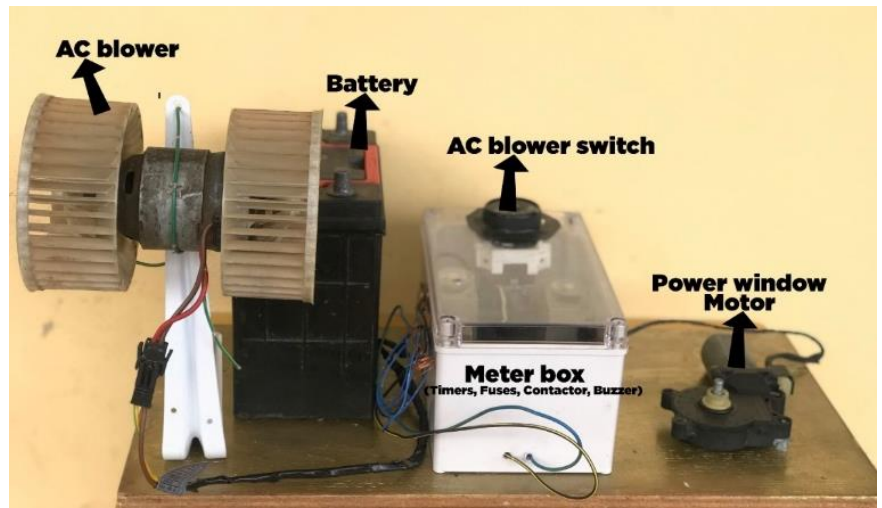

Figure 3.1 automated power window circuit for automobiles with air conditioning.

\section{III.CONCLUSION}

The conclusion arrived at a constructed circuit that automatically closes the window of the vehicle after a few seconds when the air conditioning is switched on. Therefore, with this innovative idea, we hope it will contribute to so many upcoming innovations in the future.

\section{IV.RECOMMENDATIONS}

The circuit system is well built from very delicate electronic components; given this, it has the capability of functioning properly and last longer. Below are some recommendations that are required for the elective performance of the circuit.

1. The adequate power supply is needed for operation; therefore, the engine must be running before the air conditioning is turned on.

2. Micro-controllers can be integrated into the design to make the connections simpler.

\section{ACKNOWLEDGEMENTS}

Our thanks to the experts who have contributed towards the development of the research work. The effort that we have put in this report would not have been possible without the support and help of many individuals. We would like to extend our sincere thanks to all of them.

\section{REFERENCES}

[1]. L. I. Farfan-Cabrera, "Tribology of electric vehicles: A review of critical components, current state and future improvement trends," Tribology International, vol. 138, pp. 473-486, 2019/10/01/ 2019.

[2]. R. Crowder, "1 - Electromechanical systems," in Electric Drives and Electromechanical Systems (Second Edition), R. Crowder, Ed., ed: Butterworth-Heinemann, 2020, pp. 1-35.

[3]. A. Weckenmann, L.-P. Schmidt, and M. Bookjans, "Collaborative Research Centre 694 "Integration of electronic components into mobile systems"-Motivation and survey," Physics Procedia, vol. 5, pp. 719-726, 2010/01/01/ 2010.

[4]. A. Gurubalan, M. P. Maiya, and P. J. Geoghegan, "A comprehensive review of liquid desiccant air conditioning system," Applied Energy, vol. 254, p. 113673, 2019/11/15/ 2019.

[5]. Y. Yang, C. Ren, M. Tu, B. Luo, C. Yang, and J. Fu, "Performance analysis for a new hybrid air conditioning system in hot-humid climates by simulation," International Journal of Refrigeration, vol. 117, pp. 328-337, 2020/09/01/ 2020.

[6]. Z. Zhang, J. Wang, X. Feng, L. Chang, Y. Chen, and $\mathrm{X}$. Wang, "The solutions to electric vehicle air conditioning systems: A review," Renewable and Sustainable Energy Reviews, vol. 91, pp. 443-463, 2018/08/01/ 2018.

[7]. Y. Xie, Z. Liu, J. Liu, K. Li, Y. Zhang, C. Wu, et al., "A Self-learning intelligent passenger vehicle comfort cooling system control strategy," Applied Thermal Engineering, vol. 166, p. 114646, 2020/02/05/ 2020. 
[8]. J. Christensen and C. Bastien, "Chapter | one Vehicle Architectures, Structures, and Safety Requirements," in Nonlinear Optimization of Vehicle Safety Structures, J. Christensen and C. Bastien, Eds., ed Oxford: ButterworthHeinemann, 2016, pp. 1-49.

[9]. Z. Wang, M. Wei, F. Peng, H. Liu, C. Guo, and G. Tian, "Experimental evaluation of an integrated electric vehicle $\mathrm{AC} / \mathrm{HP}$ system operating with R134a and R407C," Applied Thermal Engineering, vol. 100, pp. 1179-1188, 2016/05/05/ 2016.

[10]. L. Haupt, M. Schöpf, L. Wederhake, and M. Weibelzahl, "The influence of electric vehicle charging strategies on the sizing of electrical energy storage systems in charging hub microgrids," Applied Energy, vol. 273, p. 115231, 2020/09/01/ 2020.

[11]. S. P. Datta and P. K. Das, "Performance of an automotive air conditioning system with the variation of state-of-charge of the storage battery," International Journal of Refrigeration, vol. 75, pp. 104-116, 2017/03/01/ 2017.

[12]. W. Li and J. Sun, "Numerical simulation and analysis of transport air conditioning system integrated with a passenger compartment," Applied Thermal Engineering, vol. 50, pp. 3745, 2013/01/10/ 2013.

[13]. M. Khamis Mansour, M. N. Musa, M. N. Wan Hassan, and K. M. Saqr, "Development of novel control strategy for multiple circuit, roof top bus air conditioning system in hot humid countries," Energy Conversion and Management, vol. 49, pp. 1455-1468, 2008/06/01/ 2008.

[14]. Z. Ghaddar, K. Ghali, and N. Ghaddar, "Impact of integrating desiccant dehumidification processes to conventional AC system on urban microclimate and energy use in Beirut city," Energy Conversion and
Management, vol. 153, pp. 374-390, 2017/12/01/ 2017.

[15]. B. C. Ng, I. Z. M. Darus, H. Jamaluddin, and H. M. Kamar, "Application of adaptive neural predictive control for an automotive air conditioning system," Applied Thermal Engineering, vol. 73, pp. 1244-1254, 2014/12/05/ 2014.

[16]. K. A. Joudi, A. S. K. Mohammed, and M. K. Aljanabi, "Experimental and computer performance study of an automotive air conditioning system with alternative refrigerants," Energy Conversion and Management, vol. 44, pp. 2959-2976, 2003/11/01/ 2003.

\section{Cite this article as :}

Joseph Sekyi-Ansah, James Kwasi Quaisie, Isaac Eduyah1 Mohammed Okoe Alhassan, Eric Quansah, Esther Kyere Andoh-Acquah, "Design Modification of Automated Power Window Circuit System for Automobiles Air -Condition.", International Journal of Scientific Research in Science and Technology (IJSRST), Online ISSN : 2395-602X, Print ISSN : 23956011, Volume 7 Issue 4, pp. 264-270, July-August $2020 . \quad$ Available at doi : https://doi.org/10.32628/IJSRST207474 Journal URL : http://ijsrst.com/IJSRST207474 